\title{
Co-administration of alfentanil-propofol improves laryngeal mask airway insertion compared to fen- tanyl-propofol
}

\author{
[La co-administration d'alfentanil et de propofol, comparée à celle de fentanyl et \\ de propofol, améliore l'insertion du masque laryngé]
}

Jacqueline K.L. Hui MBBS, ${ }^{*}$ Lester A.H. Critchley MD FFARCSI, ${ }^{*}$ Manoj K. Karmakar MBBS FCRA, * Patrick K.K. Lam MBBS FANZCA $†$

Purpose: Insertion of the laryngeal mask airway (LMA) requires sufficient depth of anesthesia to relax the jaw and obtund airway reflexes. Recent studies suggest that the short-acting opioid alfentanil provides the best insertion conditions. We therefore compared the insertion conditions following co-administration of alfentanil-propofol with more commonly used fentanyl-propofol.

Methods: One hundred forty ASA I or II patients, age |8-8| yr, requiring minor surgery were recruited. They were randomized to receive either alfentanil $\left(10 \mu \mathrm{g} \cdot \mathrm{kg}^{-1} ; n=73\right)$ or fentanyl $\left(1 \mu \mathrm{g} \cdot \mathrm{kg}^{-1}\right.$; $n=67$ ) with propofol $\left(2.5 \mathrm{mg} \cdot \mathrm{kg}^{-1}\right) 90 \mathrm{sec}$ prior to LMA (size 3 or 4) insertion. A six variable (mouth opening, ease of insertion, swallowing, coughing, movement and laryngospasm) three-point (nil / partial / total) score was used to assess insertion conditions. Duration of postinsertion apnea was recorded. Insertion conditions were compared using Chi-square for trends.

Results: The two groups were demographically similar. Mouth opening and ease of insertion were not improved with alfentanil co-administration. Alfentanil-propofol reduced the incidence of swallowing, gagging, movement and laryngospasm $(P<0.05)$, with 29\% (alfentanil) compared to $45 \%$ (fentanyl) of patients responding $(P=0.05)$ to LMA insertion. Apnea [mean (SD)] following alfentanil lasted I 54 ( I 39) sec compared to $82(6 \mathrm{I}) \mathrm{sec}$ following fentanyl $(P=0.00 \mathrm{I})$.

Conclusion: Co-administration of alfentanil-propofol provided better insertion conditions than fentanyl-propofol, though apnea was prolonged by $72 \mathrm{sec}$.

Objectif : L'insertion du masque laryngé (ML) nécessite une profondeur d'anesthésie suffisante pour obtenir le relâchement de la mâchoire et l'affaiblissement des réflexes des voies aériennes. Des études récentes font penser que l'alfentanil, opiö̈de d'action brève, permet les meilleures conditions d'insertion. Nous avons donc comparé les conditions d'insertion à la suite de la co-administration d'alfentanil-propofol et de la combinaison plus courante de fentanyl-propofol.

Méthode : Cent quarante patients d'état physique ASA I ou II, de 18 à 81 ans, devant subir une intervention mineure, ont été recrutés pour l'étude. Ils ont reçu de façon aléatoire, soit de l'alfentanil $\left(10 \mu \mathrm{g} \cdot \mathrm{kg}^{-1}\right.$; n $=73)$ soit du fentanyl $\left(\mid \mu g \cdot \mathrm{kg}^{-1} ; n=67\right)$ avec du propofol $(2,5$ $\mathrm{mg} \cdot \mathrm{kg}^{-1}$ ) $90 \mathrm{~s}$ avant l'insertion du ML de taille 3 ou 4. Une cotation à six variables (ouverture de la bouche, facilité d'insertion, dég/utition, toux, mouvement et laryngospasme) et trois points (nil / partiel / total) a été utilisée pour évaluer les conditions d'insertion. La durée de l'apnée postinsertion a été notée. Les conditions d'insertion ont été comparées en utilisant le khi carré pour la tendance.

Résultats : Les deux groupes présentaient des caractéristiques démographiques similaires. L'ouverture de la bouche et la facilité d'insertion n'ont pas été améliorées avec la co-administration d'alfentanil. La combinaison alfentanil-propofol a réduit l'incidence de déglutition, de haut-le-cœur, de mouvement et de laryngospasme $(P<0,05)$, et $29 \%$ (alfentanil) comparés à $45 \%$ (fentanyl) des patients ont réagi à l'insertion du $M L(P=0,05)$. L'apnée [moyenne (écart type)] qui a suivi l'administration d'alfentanil a duré 154 (139) s et 82 (6 I) s après le fentanyl $(P=0,00$ I).

Conclusion : La co-administration d'alfentanil-propofol permet de meilleures conditions d'insertion que celle du fentanyl-propofol, bien que l'apnée soit prolongée de $72 \mathrm{~s}$.

From the Department of Anaesthesia and Intensive Care, ${ }^{*}$ The Chinese University of Hong Kong, Prince of Wales Hospital, Shatin, and the Department of Anaesthesia and Intensive Care, $†$ Tuen Mun Hospital, Tuen Mun, New Territories, Hong Kong, Peoples Republic of China. Address correspondence to: Dr. Lester A.H. Critchley, Department of Anaesthesia and Intensive Care, The Chinese University of Hong Kong, Prince of Wales Hospital, Shatin, New Territories, Hong Kong, SAR, Peoples Republic of China. Phone: 852-2632-2735; Fax: 852-2637-2422; E-mail: hcritchley@cuhk.edu.hk Accepted for publication December 20, 2001.

Revision accepted for February 1, 2002. 


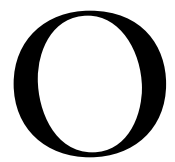

NE of the more significant advances in anesthetic practice in recent years has been the introduction of the laryngeal mask airway (LMA) by Brain in the late 1980's. ${ }^{1}$

Yet, insertion of a LMA is not always straightforward and requires sufficient depth of anesthesia for the jaw muscles to relax and the inserted LMA to be tolerated within the hypopharynx, without undue coughing, gagging, breath holding and patient movement. ${ }^{1,2}$ Such conditions are normally provided by a generous dose of an $i v$ anesthetic induction agent and recent studies have shown propofol $\left(2.5 \mathrm{mg} \cdot \mathrm{kg}^{-1}\right)$ to be superior to thiopentone $\left(5 \mathrm{mg} \cdot \mathrm{kg}^{-1}\right)$ in this respect. ${ }^{3,4}$ To further improve LMA insertion conditions, a number of adjuncts to induction, such as lidocaine, midazolam, low doses of muscle relaxant and opioids ${ }^{5-8}$ have been advocated. Of these, the opiates are most commonly used. In general, adjuncts increase successful insertion rates to over $90 \% .^{5-9}$

Recent data from our department has shown that the short acting opiate fentanyl $\left(\mathrm{l} \mu \mathrm{g} \cdot \mathrm{kg}^{-1}\right)$ with propofol $\left(2.5 \mathrm{mg} \cdot \mathrm{kg}^{-1}\right)$ given $90 \mathrm{sec}$ prior to LMA insertion provided excellent conditions (i.e., easy insertion with minimal patient response) in $77 \%(23 / 30)$ of patients. ${ }^{\mathrm{A}}$ However, recently published data by Sivalingham et al. ${ }^{10}$ and Ang et al. ${ }^{11}$ suggest that this success rate can be further improved to $88-96 \%$ by using the short-acting opiate alfentanil, instead of fentanyl. The objective of our study was to compare the LMA insertion conditions provided by propofol $\left(2.5 \mathrm{mg} \cdot \mathrm{kg}^{-1}\right)$ co-administered with alfentanil $\left(10 \mu \mathrm{g} \cdot \mathrm{kg}^{-1}\right) v s$ fentanyl $\left(1 \mu \mathrm{g} \cdot \mathrm{kg}^{-1}\right)$.

\section{Methods}

The study was conducted in two medical centres in Hong Kong, the Prince of Wales Hospital and Tuen Mun Hospital. Local Ethical Committee approval for the study was obtained from both centres. Written informed consent was obtained from all patients. One hundred forty ASA class I and II adult patients were recruited, 61 from the Prince of Wales and 79 from Tuen Mun. They were all scheduled for minor surgery in which spontaneous ventilation using a LMA was the most appropriate technique. Patients with anticipated difficult airway, as determined by a Mallampati score of 3 or more, were excluded. ${ }^{12}$

\footnotetext{
A Data was presented at the National Scientific Congress of the South African Society of Anaesthetists in Durban 1998 by Chu MC, Cheung VYN and Cheam EWS as an abstract entitled: "Randomized double-blind comparison of fentanyl, morphine or placebo to facilitate laryngeal mask airway insertion following propofol induction".
}

All patients were fasted for over six hours and no premedication was prescribed. One of two identical $10 \mathrm{~mL}$ syringes containing either alfentanil $10 \mu \mathrm{g} \cdot \mathrm{kg}^{-1}$ or fentanyl $\mathrm{l} \mu \mathrm{g} \cdot \mathrm{kg}^{-1}$, made up to $10 \mathrm{~mL}$ with normal saline, was randomly selected as the study drug. The content of the syringe was decoded after the study. Standard anesthetic monitoring was applied and the patient pre-oxygenated for three minutes. The study drug, followed by propofol $2.5 \mathrm{mg} \cdot \mathrm{kg}^{-1}$, without additives, was injected intravenously over ten seconds and flushed with normal saline. The patient was not ventilated and $90 \mathrm{sec}$ later a lubricated LMA, size 3 for females or size 4 for males, was inserted by one of the authors using the technique described by Brain. ${ }^{1,9}$

The study investigator assessed insertion conditions using a six-variable, three-point score which graded mouth opening, ease of LMA insertion and patient response: i.e., swallowing, gagging-coughing, head/limb movement and laryngospasm. The percentage of patients exhibiting each response was calculated. The position of the LMA was checked by observing respiratory movements and chest expansion. Any malpositioned or non-functioning LMA was removed, the patient given a further dose of propofol $1 \mathrm{mg} \cdot \mathrm{kg}^{-1}$ and, $60 \mathrm{sec}$ later, reinsertion attempted. The number of attempts for successful insertion was noted.

Once the LMA had been successfully inserted, the patient was intermittently ventilated via the LMA to maintain the arterial oxygen saturation above $95 \%$ and the end-tidal carbon dioxide concentration between 5.3-6.6 kPa until resumption of spontaneous respiration. Following successful LMA insertion, the duration of apnea until regular spontaneous respiration resumed was recorded. Anesthesia was then maintained with $1.5 \%$ isoflurane and $70 \%$ nitrous oxide in oxygen. Surgery was allowed to start before spontaneous respiration resumed.

The patient's blood pressure and heart rate were recorded before induction of anesthesia, one minute after induction and one minute after successful LMA insertion.

Statistical analysis was performed using Statview 4.02 (Abacus Concepts, Inc., USA). Previous studies had shown a success rate for fentanyl of $77 \%^{\mathrm{A}}$ compared with $88-96 \%$ for alfentanil. ${ }^{10,11}$ Based on these data, a sample size of $n=140$ was required to show an improvement in success rate of $15 \%$ with $\alpha=0.05$ and a power of $80 \%$. The number and percentage of patients with each score for all six variables were calculated. Insertion scores were then compared using Chi-square for trends. ${ }^{13}$ This adaptation of the Chisquared test takes into account the ranking of categories, such as easy to difficult to impossible. Blood 
TABLE I Patient demographics and ASA status for alfentanil and fentanyl co-administration. No significant difference between groups

\begin{tabular}{lll}
\hline & $\begin{array}{l}\text { Alfentanil } \\
n=73\end{array}$ & $\begin{array}{l}\text { Fentanyl } \\
n=67\end{array}$ \\
\hline Age $(\mathrm{yr})$ & $36(11)$ & $35(12)$ \\
Weight $(\mathrm{kg})$ & $61(11)$ & $58(10)$ \\
Height $(\mathrm{cm})$ & $162(9)$ & $159(10)$ \\
Gender $(\mathrm{male} /$ female $)$ & $29: 44$ & $20: 47$ \\
ASA grade $(\mathrm{I} / \mathrm{II})$ & $53: 18$ & $51: 14$ \\
\hline
\end{tabular}

Results presented as mean (SD) or ratios.

TABLE II LMA insertion conditions following either alfentanil or fentanyl co-administration. Assessments used a six variables/three-grade score

\begin{tabular}{llll}
\hline Assessment grades & Alfentanil & Fentanyl & P value \\
\hline $\begin{array}{l}\text { Mouth opening } \\
\text { (full / partial / nil) }\end{array}$ & $39 / 32 / 2$ & $34 / 33 / 0$ & 0.99 \\
$\begin{array}{l}\text { Overall ease } \\
\text { (easy / difficult / impossible) }\end{array}$ & $50 / 20 / 3$ & $39 / 27 / 1$ & 0.41 \\
$\begin{array}{l}\text { Swallowing } \\
\text { (nil / slight / gross) }\end{array}$ & $55 / 17 / 1$ & $45 / 13 / 9$ & 0.05 \\
$\begin{array}{l}\text { Gagging \& coughing } \\
\text { (nil / slight / gross) }\end{array}$ & $65 / 8 / 0$ & $51 / 10 / 6$ & 0.01 \\
$\begin{array}{l}\text { Head \& limb movement } \\
\text { (nil / slight / gross) }\end{array}$ & $65 / 6 / 2$ & $47 / 7 / 13$ & 0.001 \\
$\begin{array}{l}\text { Laryngospasm } \\
\text { (nil / partial / total) }\end{array}$ & $71 / 2 / 0$ & $57 / 7 / 3$ & 0.008 \\
\hline
\end{tabular}

LMA = laryngeal mask airway. Results represent number of individuals for each variable/grade.

pressure and heart rate changes during insertion were compared using analysis of variance for repeated measures, with Bonferroni-Dunn for post-hoc comparisons. Data are presented as mean (SD or range) and a $P<0.05$ was considered significant.

\section{Results}

Data were collected from 140 patients, aged 18-81 yr. Surgical procedures included 66 gynecological, 41 orthopedic, 16 incision and drainage of abscess, 11 general surgical and six urological operations. Sixtyseven patients received $i v$ alfentanil and 73 received iv fentanyl. The two patient groups were similar with respect to age, weight, height, gender and ASA physical status (Table I).

Mouth opening was not ideal (partial or nil) in 34 out of 73 patients $(47 \%)$ receiving alfentanil compared with 33 out of 67 patients $(49 \%)$ receiving fentanyl $(P$ $=$ NS). Similarly, LMA insertion was not ideal (difficult or impossible) in 23 patients $(32 \%)$ receiving alfentanil compared with 28 patients $(42 \%)$ receiving fentanyl $(P=$ NS; Table II $)$.

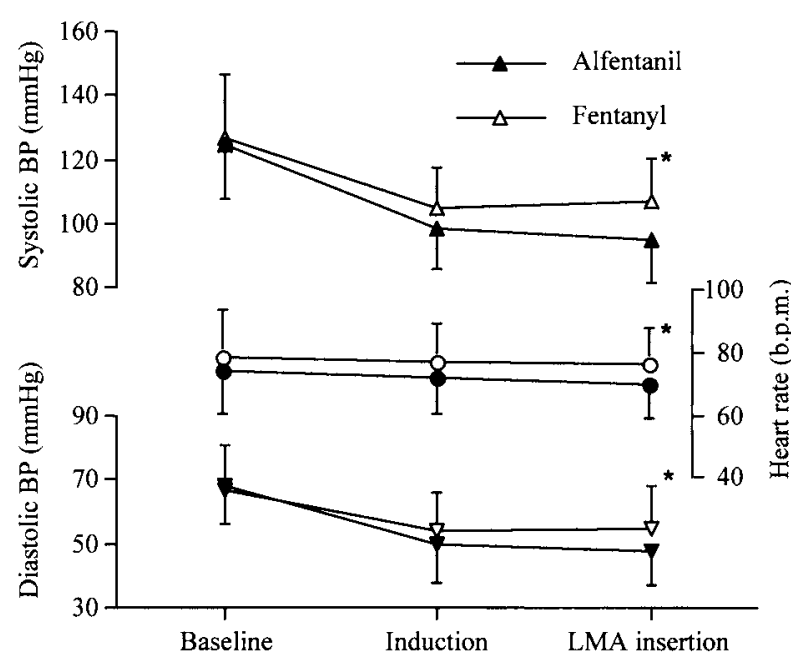

FIGURE Blood pressure (BP) and heart rate changes [mean (SD)] pre- and one-minute postinduction and one- minute post LMA insertion. ${ }^{*}=$ significant difference between groups $(P<$ $0.05)$.

LMA insertion resulted in the patient responding by either swallowing, gagging-coughing, movement or laryngospasm in 21 out of 73 patients $(29 \%)$ receiving alfentanil compared with 30 out of 67 patients $(45 \%)$ receiving fentanyl $(P=0.05)$. The incidence of swallowing was $25 \%$ with alfentanil vs $33 \%$ with fentanyl $(P=0.05)$, coughing or gagging was $11 \%$ vs $24 \%$ $(P=0.01)$, movement of the head or limbs was $11 \%$ vs $30 \%(P=0.001)$ and laryngospasm was $3 \%$ vs $15 \%$ $(P=0.008$; Table II $)$.

LMA insertion was unsuccessful on the first attempt in four patients receiving alfentanil compared with six patients receiving fentanyl $(P=0.7)$. It was totally unsuccessful and an alternative method of airway management was required in three alfentanil and two fentanyl patients $(P=0.8)$.

Apnea following LMA insertion lasted 154 (139) sec in patients receiving alfentanil compared with 82 (61) sec in patients receiving fentanyl $(P=0.0002)$.

Systolic and diastolic blood pressures decreased following induction in both groups $(P<0.0001)$. The decreases in blood pressure were greater in those patients receiving alfentanil $(P<0.05$; Figure $)$. Heart rate decreased only in those patients that received alfentanil $(P=0.0016$; Figure $)$.

\section{Discussion}

We have shown that propofol $\left(2.5 \mathrm{mg} \cdot \mathrm{kg}^{-1}\right) \mathrm{co}^{-}$ administered with alfentanil $\left(10 \mu \mathrm{g} \cdot \mathrm{kg}^{-1}\right)$, compared 
with propofol and fentanyl $\left(1 \mu \mathrm{g} \cdot \mathrm{kg}^{-1}\right)$, reduced the number of patients who respond adversely to LMA insertion from $45 \%$ to $29 \%$, though mouth opening and ease of insertion were not improved. Duration of apnea following insertion was increased from $82 \mathrm{sec}$ using fentanyl to $154 \mathrm{sec}$ using alfentanil.

We used a methodology similar to that developed by previous LMA researchers to assess insertion conditions. ${ }^{8,10}$ Early investigators confined their assessment to mouth opening, gagging and coughing ${ }^{3,4}$ but, recently, a six- variable/three-grade score was developed (Table II) ${ }^{8,10}$ With some modification to include swallowing, we were able to use this score to assess both the ease of placement and the patient's response.

Few authors have studied the effects of alfentanil co-administration on LMA insertion. In 1996 Driver et al. studied the effects of alfentanil $\left(10 \mu \mathrm{g} \cdot \mathrm{kg}^{-1}\right)$ on LMA insertion, which they compared to those of midazolam $\left(0.04 \mathrm{mg} \cdot \mathrm{kg}^{-1}\right){ }^{7}$ They concluded that a combination of alfentanil with midazolam reduced propofol requirements and improved insertion conditions. ${ }^{7}$ The same authors, a year later, used alfentanil when comparing propofol with thiopentone for LMA insertion. ${ }^{14}$ In 1999 Ang et al. showed that alfentanil in doses of 5 and $10 \mu \mathrm{g} \cdot \mathrm{kg}^{-1}$ with propofol improved mouth opening and reduced patient responses. ${ }^{11}$ In the same year, Sivalingam et al. used alfentanil coadministration in doses of $5 \mu \mathrm{g} \cdot \mathrm{kg}^{-1}$ to compare propofol with sevoflurane inhalation for LMA insertion and showed that alfentanil improved insertion conditions with both induction techniques. ${ }^{10}$

In the present study mouth opening was recorded as non-ideal in nearly half $(47-49 \%)$ of our patients. Insertion of the LMA was not easily performed in $32 \%$ of patients receiving alfentanil compared to $42 \%$ of patients receiving fentanyl, though this difference was not statistically significant. Our incidence of difficult LMA insertion is higher than that reported previously. Ang et al. reported a $20 \%$ incidence of difficult insertion when co-administering alfentanil $10 \mu \mathrm{gg} \cdot \mathrm{kg}^{-1} \mathrm{ll}^{11}$ and Sivalingham et al. reported a $28 \%$ incidence of difficult jaw opening when using alfentanil $5 \mu \mathrm{g} \cdot \mathrm{kg}^{-1}$ and a $4 \%$ incidence of difficult insertion. ${ }^{10}$ However, the latter author did wait until the jaw was fully relaxed by giving additional boluses of propofol before inserting the LMA. Our higher incidence of reported difficulty with mouth opening and insertion may reflect stricter study criteria. In addition, we frequently encountered difficulty in passing the LMA cuff between the patients front incisors, which we attribute to our patients being mainly ethnic Chinese who, in our experience, have smaller jaws than the Caucasian population for whom the LMA was originally designed. However, a number of authors have reported recently much lower incidences of difficulty when using doses of propofol of 2.5 to $3.5 \mathrm{mg} \cdot \mathrm{kg}^{-1}$, suggesting that our $2.5 \mathrm{mg} \cdot \mathrm{kg}^{-1}$ dose was at the lower end of the acceptable range and that a larger dose may be beneficial. ${ }^{15,16}$

The main positive finding of our study was the reduced number of patients that responded adversely to LMA insertion, $45 \%$ with fentanyl compared to $29 \%$ with alfentanil. We graded four fundamental patient responses to LMA insertion: swallowing, coughing-gagging, movement and laryngospasm. Swallowing was the response that we encountered most frequently (Table II). This was not surprising as swallowing is the natural response to a food bolus entering the hypopharynx and the cuff of the LMA acts similarly, triggering this response if the patient is insufficiently anesthetized. ${ }^{2}$ Some anesthesiologists take advantage of this reflex and use swallowing as an indication of emergence from anesthesia when using the LMA. ${ }^{2}$ Coughing and gagging are more potent reflexes, triggered by irritation of the larynx or epiglottis and prevents foreign material entering the trachea and lungs. The LMA is designed to avoid triggering coughing and gagging because its cuff sits posterior to the larynx in the hypopharynx, as evidenced by the observed low incidence of coughing and gagging. Patient movement was more commonly encountered when using fentanyl $(30 \%$ vs $11 \%)$ and laryngospasm was the least frequent response. It is not uncommon for LMA insertion to cause some transient cord closure or partial laryngospasm, which was more frequent with fentanyl. ${ }^{2}$ However, total laryngospasm only occurred in three patients receiving fentanyl.

Our study supports the hypothesis that alfentanilpropofol co-administration is more effective than fentanyl- propofol at suppressing reflex responses to LMA insertion. The dosages of alfentanil $\left(10 \mu \mathrm{g} \cdot \mathrm{kg}^{-1}\right)$ and fentanyl $\left(1 \mu \mathrm{g} \cdot \mathrm{kg}^{-1}\right)$ used in the study were chosen because they had been used successfully in previous LMA studies, $3,4,7,11, \mathrm{~A}$ and were convenient to calculate in a clinical setting. However, these two doses are not equipotent. According to Stanski et al., alfentanil is five to six times less potent than fentanyl. ${ }^{17}$ Also, due to differences in $\mathrm{pKa}$, the speed of onset following iv administration of alfentanil is two to three times more rapid than fentanyl, resulting in times of onset of one to two minutes, compared to five to six minutes for fentanyl. ${ }^{18}$ In our study, we required an onset of effect by two minutes. Furthermore, the more rapid onset time of alfentanil allows a relatively smaller drug mass to be administered to achieve a similar clinical end point. ${ }^{19}$ Thus, in theory, a greater depth of anesthesia and reflex suppression is to be 
expected at the moment of LMA insertion when using alfentanil according to our study protocol. Possibly smaller doses of alfentanil $\left(<10 \mu \mathrm{g} \cdot \mathrm{kg}^{-1}\right)$ are equally efficacious in facilitating LMA insertion and with less prolongation of the apnea time. This is a hypothesis that merits further investigation.

Blood pressure and heart rate are usually reported to increase by $0-20 \%$ following LMA insertion and by $25-50 \%$ following tracheal intubation. ${ }^{2}$ Following alfentanil co-administration decreases in blood pressure and heart rate were observed (Figure). Interestingly, Ang et al. found that $14 \%$ of patients receiving 10 $\mu \mathrm{g} \cdot \mathrm{kg}^{-1}$ of alfentanil with propofol developed bradycardias requiring atropine. ${ }^{11}$ However, these authors only waited $60 \mathrm{sec}$ before inserting the LMA, which may have been insufficient. We waited $90 \mathrm{sec}$ and no bradycardias were observed using a similar alfentanil dose.

The main problem when using alfentanil, other than increased cost, was the prolongation of apnea from $82 \mathrm{sec}$ to $154 \mathrm{sec}$. However, we did not find this delay to be a major clinical inconvenience.

Despite the advantages of using opiate co-administration,,$^{7,10,14}$ in five patients (3.5\%) LMA insertion remained unsuccessful. We believe that this represents a small percentage of patients, common to all studies, in whom upper airway anatomy is unfavourable and successful LMA insertion is not possible.

In conclusion, co-administration of alfentanilpropofol provides better LMA insertion conditions than fentanyl- propofol.

\section{References}

1 Brain AIJ, McGhee TD, McAteer EJ, Thomas A, AbuSaad MAW, Bushman JA. The laryngeal mask airway. Development and preliminary trials of a new type of airway. Anaesthesia 1985; 40: 356-61.

2 Brimacombe J, Berry A. The laryngeal mask airway anatomical and physiological implications. Acta Anaesthesiol Scand 1996; 40: 201-9.

3 Brown GW, Patel N, Ellis FR. Comparison of propofol and thiopentone for laryngeal mask insertion. Anaesthesia 1991; 46: 771-2.

4 Scanlon P, Carey M, Power M, Kirby F. Patient response to laryngeal mask insertion after induction of anaesthesia with propofol or thiopentone. Can J Anaesth 1993; 40: 816-8.

5 Stoneham MD, Bree SE, Sneyd JR. Facilitation of laryngeal mask insertion. Effects of lignocaine given intravenously before induction with propofol. Anaesthesia 1995; 50: 464-6.

6 Godsiff L, Magee L, Park GR. Propofol versus propofol with midazolam for laryngeal mask insertion. Eur J Anaesth 1995; 12(Suppl 12): 35-40.
7 Driver IK, Wiltshire S, Mills P, Lillywhite N, HowardGriffin R. Midazolam co-induction and laryngeal mask insertion. Anaesthesia 1996; 51: 782-4.

8 Chui PT, Cheam EWS. The use of low-dose mivacurium to facilitate insertion of the laryngeal mask airway. Anaesthesia 1998; 53: 486-510.

9 Brimacombe J, Berry A. Insertion of the laryngeal mask airway - a prospective study of four techniques.

Anaesth Intensive Care 1993; 21: 89-92.

10 Sivalingham P, Kandasamy R, Madhaven G, Dhakshinamoorthi P. Conditions for laryngeal mask insertion. A comparison of proprofol versus sevoflurane with or without alfentanil. Anaesthesia 1999; 54: 271-6.

11 Ang S, Cheong KF, Ng TI. Alfentanil co-induction for laryngeal mask insertion. Anaesth Intensive Care 1999; 27: 175-8.

12 Mallampati SR, Gatt SP, Gugino LD, et al. A clinical sign to predict difficult tracheal intubation: a prospective study. Can Anaesth Soc J 1985; 32: 429-34.

13 Altman DG. Comparing groups - categorical data. In: Altman DG (Ed). Practical Statistics for Medical Research, $1^{\text {st }}$ ed. London: Chapman \& Hall, 1991: 261-5.

14 Driver I, Wilson C, Wiltshire S, Mills P, Howard-Griffin $R$. Co-induction and laryngeal mask insertion. A comparison of thiopentone versus propofol. Anaesthesia 1997; 52: 698-700.

15 Keller C, Sparr HJ, Luger TJ, Brimacombe J. Patient outcomes with positive pressure versus spontaneous ventilation in non-paralysed adults with the laryngeal mask. Can J Anaesth 1998; 45: 564-7.

16 Ti LK, Chow MYH, Lee TL. Comparison of sevoflurane with propofol for laryngeal mask airway insertion in adults. Anesth Analg 1999; 88: 908-12.

17 Stanski DR. The clinical pharmacology of alfentanil. Eur J Anaesthesiol 1987; 1(Suppl 1): 3-11.

18 Stanski DR, Hug CC. Alfentanil - a kinetically predictable narcotic analgesic (Editorial). Anesthesiology 1982; 57: 435-8.

19 Shafer SL, Varvel JR. Pharmacokinetics, pharmacodynamics, and rational opioid selection. Anesthesiology 1991; 74: 53-63. 